\title{
Rock fragmentation mechanisms and an experimental study of drilling tools during high-frequency harmonic vibration
}

\author{
Li Wei ${ }^{1}$, Yan Tie ${ }^{1 *}$, Li Siqi ${ }^{1 * *}$ and Zhang Xiaoning ${ }^{2}$ \\ ${ }^{1}$ School of Petroleum Engineering, Northeast Petroleum University, Daqing, Heilongjiang 163318, China \\ ${ }^{2}$ Research Institute of Petroleum Exploration \& Development of CNPC, Beijing 100083, China \\ (C) China University of Petroleum (Beijing) and Springer-Verlag Berlin Heidelberg 2013
}

\begin{abstract}
Resonance drilling is a new technology, still at the laboratory stage. It has great potential to improve rock fragmentation efficiency. We analyzed the amplitude-frequency characteristics of steadystate mechanical vibration excited by harmonic vibration in rocks and an apparatus was built to achieve high frequency vibration of rock. The influence of rock drillability, rotary speed, excitation frequency, and other parameters on the rate of penetration (ROP) in resonance drilling was analyzed. The results show that the rock drillability decreased with an increase in excitation frequency. When drilling with a large size drill bit, the ROP increased with excitation frequency. The ROP reached a maximum value at the resonant frequency of the rock. The ROP of the bit increased linearly with rotary speed when no vibration was applied on the rock and increased approximately exponentially when harmonic vibration was applied. In addition, the resonant frequency of the rock was changing during the process of rock fragmentation, so in order to achieve the desired resonance of the rock, it is necessary to determine an appropriate harmonic vibration excitation frequency.
\end{abstract}

Key words: Resonance drilling, high frequency excitation, amplitude-frequency characteristics, natural frequency, drillability

\section{Introduction}

Resonance is a common phenomenon in nature (Broer, 2012). Due to its negative effects, drilling parameters are generally adjusted to reduce the occurrence of resonance phenomena (Cobern et al, 2007; Gonzalez et al, 2007; Gao and Gu, 2008; Eltrissi, 2009). Resonance drilling is a technology to achieve high fragmentation efficiency of rock. Adjusting the impact frequency of drill tools to the natural vibration frequency of the rock formation causes rock resonance to occur, which results in a high rate of penetration. Resonance drilling is a special rotary drilling technique operating at a particular impact frequency interval. High-frequency vibration drilling has been applied in metals, plastics, glass and other field broadly (Ishikawa et al, 1998; Zhang and Wang, 1998; Egashira et al, 2002; Tichkiewitch et al, 2002; Wang et al, 2004). At present, resonance drilling is still in the laboratory research stage. However, the use of resonance in breaking rocks has been applied in engineering and many achievements have been obtained (Ksaibati et al, 1999; Li, 1999; Zhang, 2005).

*Corresponding author. email: yant@dqpi.edu.cn

**Corresponding author. email: lisiqi448@163.com

Received June 23, 2012
Some researchers have undertaken a series of investigations into resonance drilling (Flanders et al, 2000; Wu et al, 2000; Gonzalez et al, 2007; Wiercigroch, 2010; Zou et al, 2010). Aberdeen University carried out laboratory experiments on rock fragmentation using resonance drilling and found that the cutting rate was 10 times higher than using conventional drilling. Yang et al (2007) investigated rock fragmentation mechanisms and the effect of crack propagation on rock fragmentation in the process of resonance. However, few previous studies have considered the coupled effect of rotary shear and impact vibration on rock fragmentation. Based on the principle of mechanical vibration, a calculation model of steady state vibration response was established. By carrying out experiments, the effect of mechanical and vibration parameters on rock fragmentation during resonance drilling was analyzed. The results provide theoretical guidance for the further application of resonance drilling.

\section{Vibration response of rock in high- frequency harmonic vibration}

A high-frequency rotary resonant device can keep shearing rocks as effectively as longitudinal vibration of the drill bit. It can improve the rock breaking efficiency by combing advantages of rotary and percussive drilling (high- 
frequency impact on rock). When external excitation is introduced to a formation, vibration may occur in rock. In our test apparatus, energy input is electrical and excitation output is high-frequency vibration, as shown in Fig. 1.

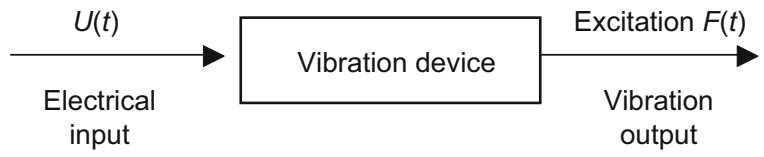

Fig. 1 The vibration system

In Fig. 1, the harmonic excitation, which the drill bit imposes on the rock in the bottom of the hole, is:

$$
F(t)=A \sin \omega t
$$

where $A$ is the external excitation amplitude; $\omega$ is the external excitation frequency, $\mathrm{Hz}$.

The motion equation of a single-degree-of-freedom system under harmonic force is described as follows ( $\mathrm{Hu}$, 2005):

$$
m \ddot{u}(t)+c \dot{u}(t)+k u(t)=F(t)
$$

where $u(t)$ is the displacement at time $t, \mathrm{~m} ; \dot{u}(t)$ is the velocity at time $t, \mathrm{~m} / \mathrm{s} ; \ddot{u}(t)$ is the acceleration at time $t, \mathrm{~m} / \mathrm{s}^{2}$; $k$ is the stiffness of rock, N/m; $m$ is the mass of the vibration system, $\mathrm{kg}$; and $c$ is a constant coefficient.

In the process of steady-state forced vibration, the rock in the bottom of the hole is subjected to a continuous harmonic external excitation and a steady-state response of the rock is generated. From Eq. (2), we obtain:

$$
\beta_{\mathrm{d}}=\frac{1}{\sqrt{\left(1-\lambda^{2}\right)^{2}+(2 \zeta \lambda)^{2}}}
$$

with

$$
\begin{aligned}
& \lambda=\frac{\omega}{\omega_{\mathrm{n}}} \\
& \beta_{\mathrm{d}}=\frac{B_{\mathrm{d}}}{A / k}
\end{aligned}
$$

where $\lambda$ is defined as the ratio of the harmonic force frequency over the undamped natural frequency of rock; $B_{\mathrm{d}}$ is the vibration amplitude, $\mathrm{m} ; \beta_{\mathrm{d}}$ is the magnification factor of the displacement amplitude; $\zeta$ is the damping ratio; and $\omega_{\mathrm{n}}$ is the natural frequency of the hole bottom rock, Hz.

The magnification factors of velocity amplitude and acceleration amplitude can be obtained from the further derivation. When $A, k, m$ and other parameters of the vibration system are given, the change of $B_{\mathrm{d}}$ with $\omega$ can be described by the relation curves between $\beta_{\mathrm{d}}$ and $\lambda$.

\section{Amplitude-frequency characteristics of steady-state rock response}

Based on Eq. (3), a plot of $\beta_{\mathrm{d}}$ versus $\lambda$ (Fig. 2) presents the most important features in forced vibration. In a low frequency stage $(0<\lambda<1)$, the displacement amplitude of forced vibration of the rock is close to the static displacement of the vibration system. The system is considered quasi-static. At this time, $\beta_{\mathrm{d}} \approx 1, \beta_{\mathrm{v}} \approx 0$ and $\beta_{\mathrm{a}} \approx 0$. In a high frequency stage $(\lambda>1)$, the rock in the bottom is excited by highfrequency harmonic vibration, the phase of acceleration of the rock is basically the same as the exciting force, but the vibration amplitude is small. At this time, $\beta_{\mathrm{d}} \approx 0, \beta_{\mathrm{v}} \approx 0$ and $\beta_{\mathrm{a}}$ $\approx 1$. In a resonance stage $(\lambda=1)$, for underdamped systems, $0<\zeta<1 / \sqrt{2} \approx 0.707$. When the excitation frequency increases slowly, the amplitudes of displacement, velocity and acceleration will reach peak values at $\lambda \approx 1$. At this time, resonance occurs, which is similar to undamped vibration. From Eq. (3), we obtain the frequency ratio when the displacement amplitude achieves maximum value.

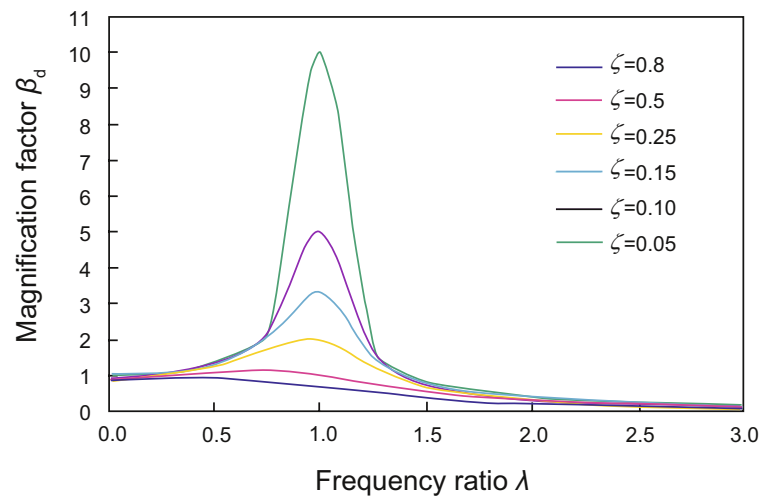

Fig. 2 Steady-state amplitude-frequency characteristics curves of vibration response

In ideal conditions, i.e. damping does not exist, the resonant frequency is equal to the natural frequency of rock. However, in actual conditions, damping does exist, then the frequency ratio of resonant frequency to natural frequency meets the following equation:

$$
\lambda_{\mathrm{d}}=\sqrt{1-2 \zeta^{2}}
$$

When $1-2 \zeta^{2}<0, \zeta>\sqrt{0.5}$, no peak is observed in the curve of $\beta_{\mathrm{d}}-\lambda$. This means that no resonance occurs for the system when $\zeta>0.707$. Moreover, the dynamic displacement is smaller than the static displacement.

\section{Experimental apparatus}

The experimental apparatus and its schematic diagram are shown in Fig. 3 and Fig. 4. The apparatus generates various vibration excitations, such as low-frequency large-amplitude vibration and high-frequency small-amplitude vibration and can be used to analyze rock fragmentation mechanism induced by a drill bit under the condition of steady-state vibration of the rock responding to external excitation.

A schematic diagram of the high-frequency vibration generator is shown in Fig. 5. The electrical power is $U(t)$ when the current flows through the low-frequency 
electromagnetic vibration exciting coil. When current flows through the super magnetostrictive rods and coils in the apparatus, it will produce high frequency vibration excitation $F(t)$, which is transferred to the rock at the bottom by the vibration transmission rod and drill bit. The vibration frequency of apparatus is $1-5,000 \mathrm{~Hz}$ and the excitation mass is $0-250 \mathrm{~kg}$.

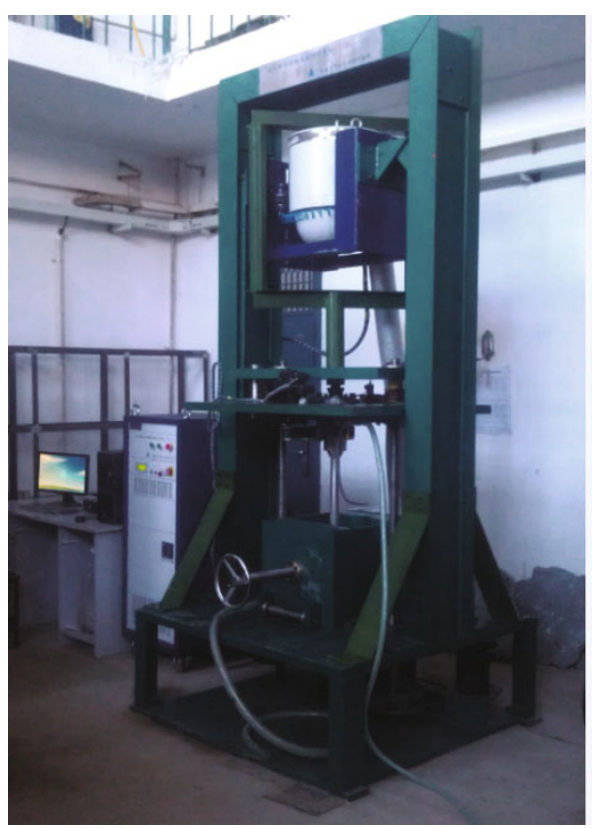

Fig. 3 The experimental vibration excitation apparatus

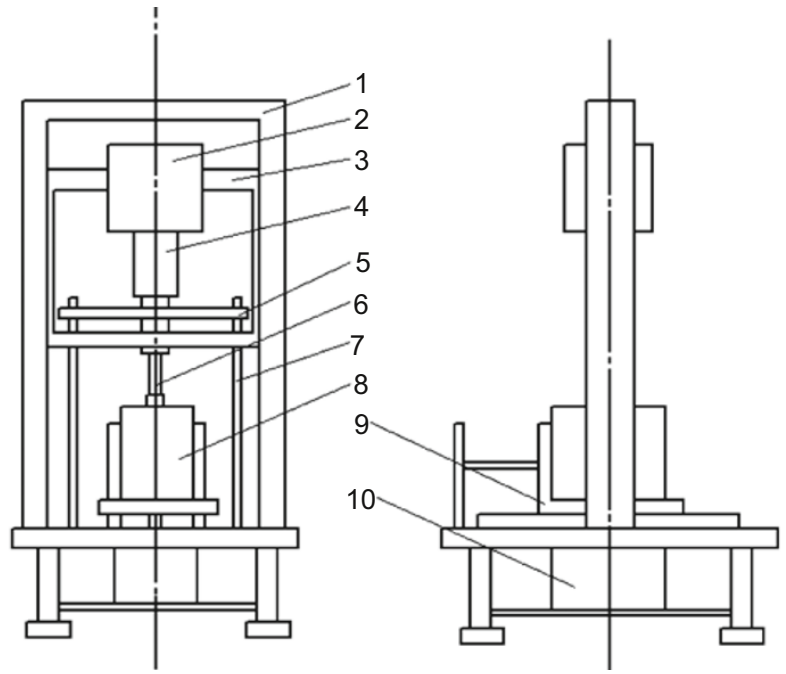

Fig. 4 Schematic diagram of the apparatus

1-Main frame, 2-Excitation table, 3-Vibration conductor, 4-Driving rod, 5-Positioning frame, 6-Drill pipe and drill bit, 7-Lead screw, 8-Rock sample, 9-Stage, 10-Motor of axle load

\section{Experimental results and discussion}

\subsection{Micro-drill bit}

Several tight sandstone core samples from the Daqing

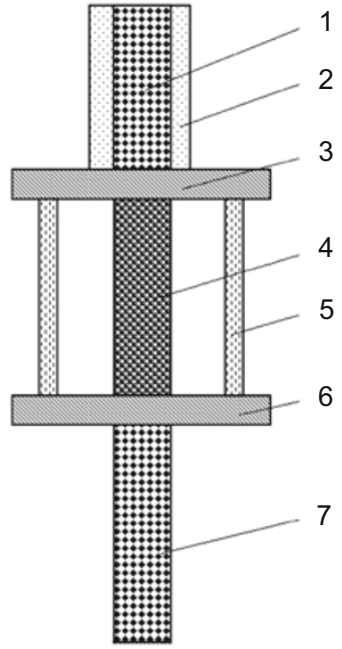

Fig. 5 Schematic diagram of a high-frequency vibration generator

1-Armature, 2-Excitation coils of low-frequency electromagnetic vibration, 3-Upper plywood, 4-Super magnetostrictive rod and coil assembly, 5-Prestress-clamping bolt, 6-Under plywood, 7-Driving rod

Oilfield were drilled with a diamond-coated micro drill bit with a diameter of $31.75 \mathrm{~mm}$. In experiments, the drilling pressure was $889.7 \mathrm{~N}$, the rotary speed was $55 \mathrm{rpm}$, the excitation frequency was $500-1,500 \mathrm{~Hz}$, and the excitation mass was $10 \mathrm{~kg}$. The time required to drill a hole of a depth of $2.4 \mathrm{~mm}$ was recorded (36-158 s). The resonant frequency of the rock sample was measured by resonance acoustic spectroscopy (Harris et al, 2005; Jerry et al, 2005; Cong et al, 2007). The basic parameters of core samples and experimental results of frequency are shown in Table 1. The micro PDC bit used and the core sample drilled are shown in Figs. 6 and 7.

Table 1 The test data of dense sandstone core samples taken from well Jishen 1

\begin{tabular}{ccccccc}
\hline Sample & $\begin{array}{c}\text { Depth } \\
\mathrm{m}\end{array}$ & Lithology & $\begin{array}{c}\text { Density } \\
\mathrm{g} / \mathrm{cm}^{3}\end{array}$ & $\begin{array}{c}\text { Young's } \\
\text { modulus } \\
\mathrm{MPa}\end{array}$ & $\begin{array}{c}\text { Drillability } \\
\text { of rock }\end{array}$ & $\begin{array}{c}\text { Resonance } \\
\text { frequency } \\
\mathrm{kHz}\end{array}$ \\
\hline $1 \#$ & 630 & Gray siltstone & 2.54 & 14086.5 & 5.2 & 1.58 \\
$2 \#$ & 836 & Gray siltstone & 2.53 & 17173.9 & 5.6 & 1.73 \\
$3 \#$ & 1007 & $\begin{array}{c}\text { Gray } \\
\text { conglomerate }\end{array}$ & 2.61 & 16326.5 & 5.8 & 1.66 \\
$4 \#$ & 1033 & $\begin{array}{c}\text { Gray sandy } \\
\text { conglomerate }\end{array}$ & 2.39 & 15064.7 & 6.1 & 1.67 \\
$5 \#$ & 1966 & $\begin{array}{c}\text { Muddy } \\
\text { siltstone }\end{array}$ & 2.67 & 28379.1 & 6.5 & 2.17 \\
$6 \#$ & 2526 & Siltstone & 2.75 & 37510.6 & 7.3 & 2.46 \\
\hline
\end{tabular}

Notes: The diameter of the micro drill bit was $31.75 \mathrm{~mm}$.

The harmonic vibration excitation wave produced by the vibration generator is shown in Fig. 8. Its amplitude was 0.1 $\mathrm{mm}$, so the wave is an excitation wave of a small amplitude and an intermediate frequency band. A size-limited dynamic load impact region, induced by this vibration, was formed on the rock sample. The periodic stress applied on the rock surface promotes the propagation of cracks from the impact region in the radial direction. This kind of impact region 


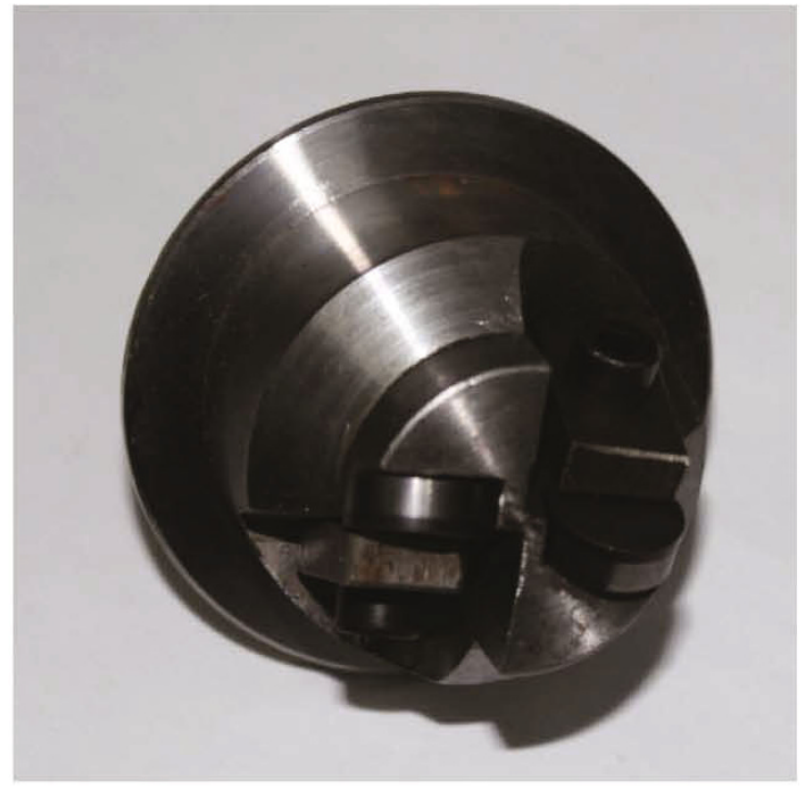

Fig. 6 Micro PDC bit

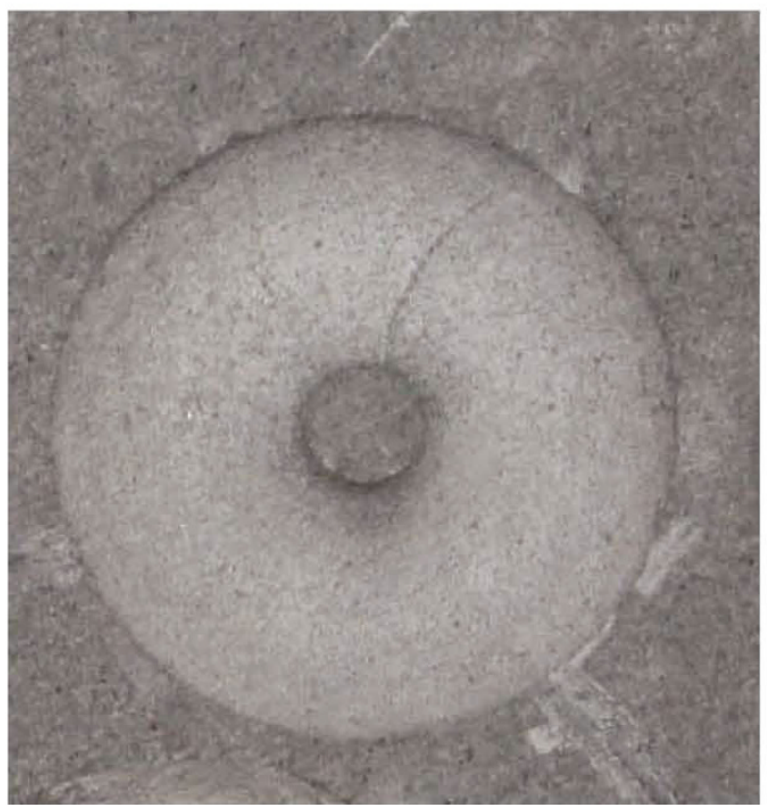

Fig. 7 The rock sample cut by the micro PDC bit (sample 1\#)

could not only improve the rock fragmentation efficiency, but also prevent the crack from propagating further to the borehole wall, this may effectively enhance wellbore stability.

Fig. 9 shows the drillability of core sample 1\# at different excitation frequencies. The drillability of rock decreased gradually with an increase in excitation frequency. In a low frequency band (less than $700 \mathrm{~Hz}$ ), the harmonic vibration frequency was far less than the low resonance frequency of rock. The response of rock to the external excitation was low and then the vibration excitation had a limited impact on the crack propagation. Therefore, the drillability of rock changed very little with vibration frequency when its value was less than $700 \mathrm{~Hz}$. When the vibration frequency reached 700 $\mathrm{Hz}$, the rock drillability decreased gradually with frequency. When the frequency reached $1,500 \mathrm{~Hz}$, the rock drillability

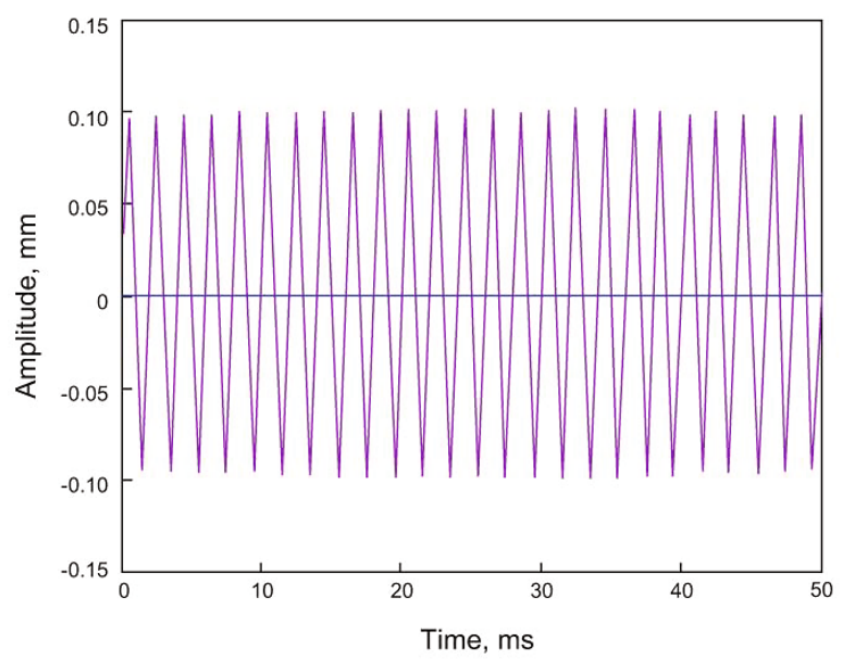

decreased by $25.6 \%$ and the rate of penetration (ROP) increased by $152 \%$.

Fig. 10 shows that the drillability of rock increased with well depth and decreased with an increase in the vibration excitation frequency.

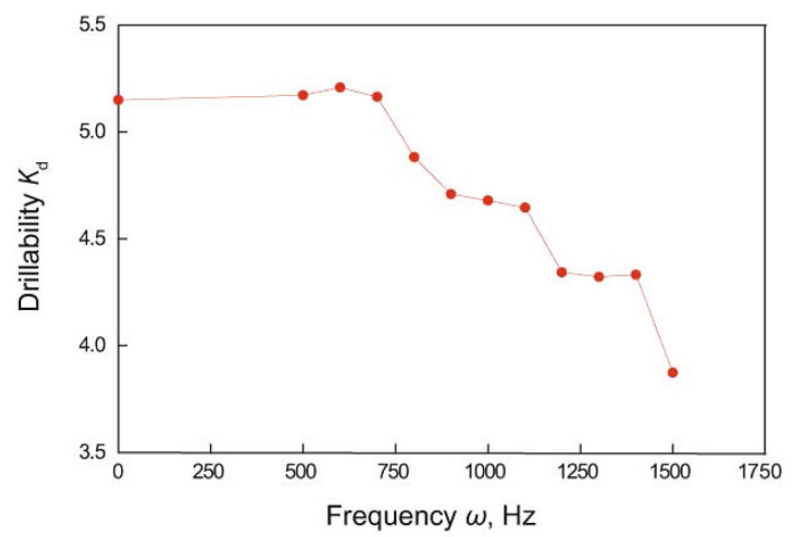

Fig. 9 The drillability of the core sample at different vibration frequencies (sample 1\#)

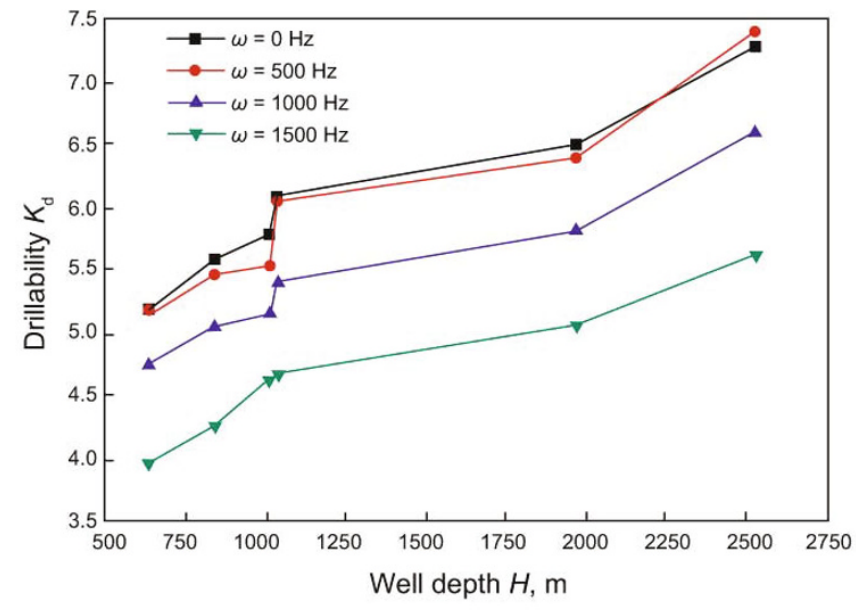

Fig. 10 The rock drillability of core samples at different frequencies (samples 1\#-6\#) 


\subsection{Large size drill bit}

In order to further analyze the effect of high frequency vibration on rock fragmentation, a large size drill bit with a diameter of $100 \mathrm{~mm}$ was used to drill a natural gray siltstone. The drilling pressure was $15 \mathrm{kN}$, the rotary speed was 120 rpm, the excitation frequency was $800-1,800 \mathrm{~Hz}$, and the excitation mass was $100 \mathrm{~kg}$. The experimental results are shown in Table 2 and Figs. 11 and 12.

Table 2 The test data of gray siltstone core samples

\begin{tabular}{ccccccc}
\hline Sample & $\begin{array}{c}\text { Depth } \\
\mathrm{m}\end{array}$ & Lithology & $\begin{array}{c}\text { Density } \\
\mathrm{g} / \mathrm{cm}^{3}\end{array}$ & $\begin{array}{c}\text { Young's } \\
\text { modulus Drillability } \\
\mathrm{MPa}\end{array}$ & $\begin{array}{c}\text { Resonance } \\
\text { frequency } \\
\mathrm{kHz}\end{array}$ \\
\hline $7 \#$ & 630 & Gray siltstone & 2.39 & 9415.8 & 5.8 & 1.40 \\
$8 \#$ & 840 & Gray siltstone & 2.41 & 9874.6 & 5.4 & 1.41 \\
$9 \#$ & 910 & Gray siltstone & 2.30 & 9486.7 & 5.6 & 1.41 \\
$10 \#$ & 1000 & Gray siltstone & 2.43 & 9920.4 & 5.5 & 1.42 \\
\hline
\end{tabular}

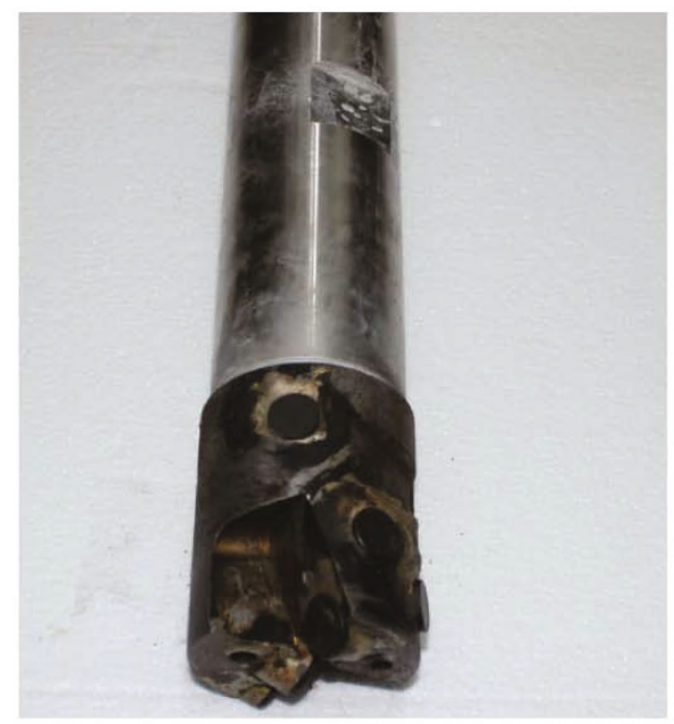

Fig. 11 100-mm-diameter PDC bit

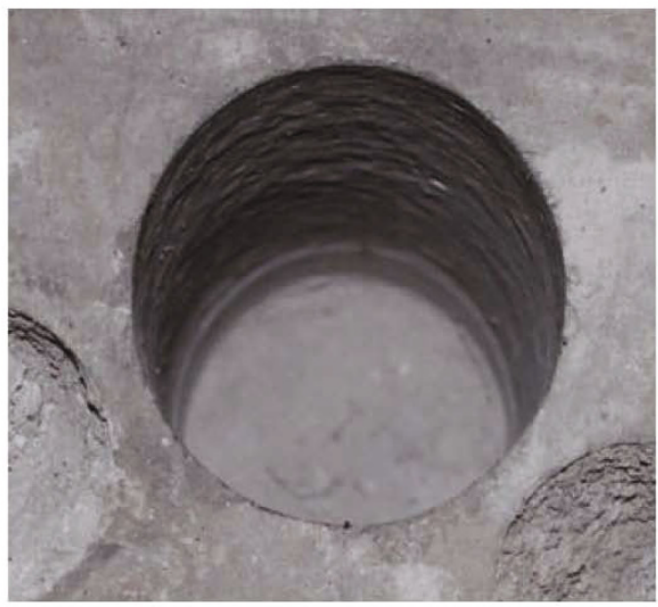

Fig. 12 The rock sample cut by a 100 -mm-diameter PDC bit (sample 7\#)
The rates of penetration (ROP) of 4 rock samples (samples $7 \#-10 \#)$ were very close to each other $(2.12,2.15,2.16$, and $2.11 \mathrm{~cm} / \mathrm{min}$, respectively) when no harmonic vibration was applied on the rock samples. However, when the harmonic vibration was introduced, the ROP increased with an increase in the excitation frequency from $800 \mathrm{~Hz}$ and the ROP achieved a maximum value at a vibration frequency of 1,400 $\mathrm{Hz}$ (Fig. 13). The ROP increased by $93 \%-106 \%$. This showed that the ROP was not only affected by the excitation mass, but also by the excitation frequency.

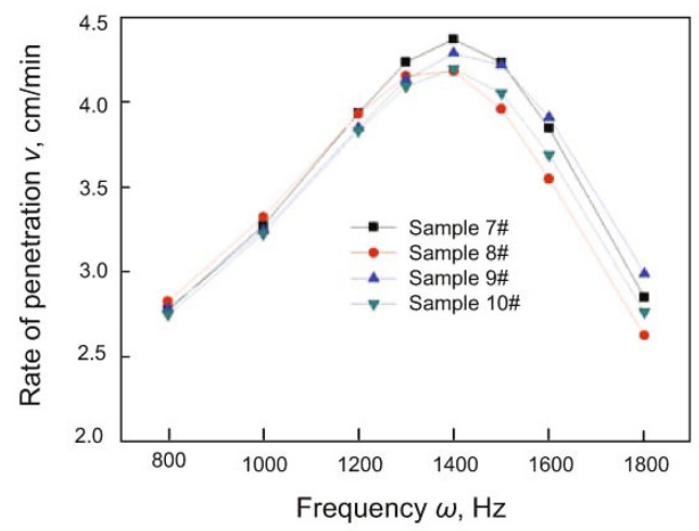

Fig. 14 shows that the ROP of the large size drill bit increased with an increase in rotary speed. The large size drill bit achieved the highest ROP at a vibration frequency of $1,400 \mathrm{~Hz}$. The ROP of the bit increased linearly with rotary speed when no vibration was applied on the rock sample and increased approximately exponentially when harmonic vibration was applied. When the rotary speed was approximately $200 \mathrm{rpm}$, the rate of increase of ROP reduced. The bit ROP increased by $144 \%$ at $200 \mathrm{rpm}$ and $1,400 \mathrm{~Hz}$, compared with drilling a hole when no excitation was applied.

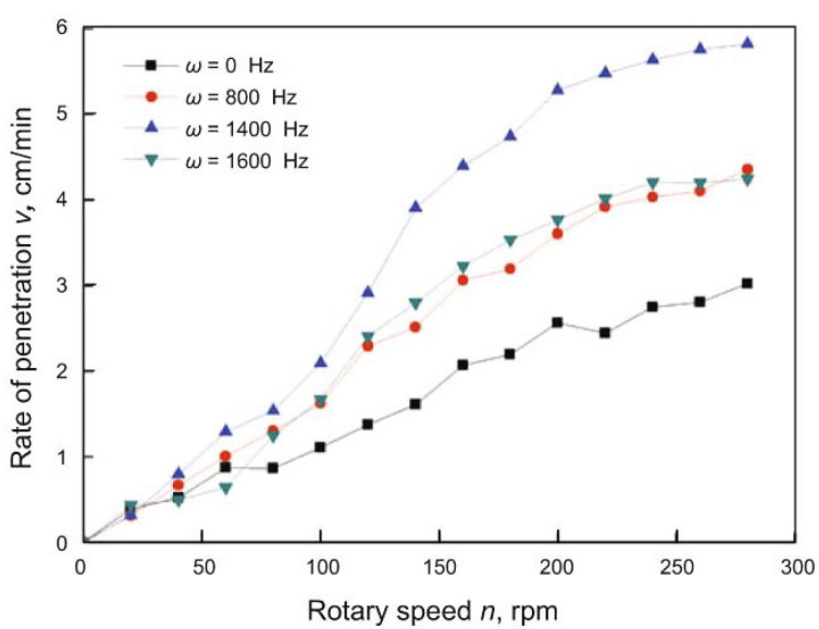

Fig. 14 ROP of the large size drill bit at different rotary speeds and different frequencies (sample 7\#) 
Fig. 15 shows the rock fragmentation mechanism due to resonance. From the figure we can see that in the process of rock vibration, if no crack exists on the rock surface, the curve shape of harmonic vibration excitation which is affected by the rock at the bottom is shown in Fig. 2. It is namely the original amplitude-frequency curve path. This does not accord with practical drilling obviously. In the process of percussive-rotary rock cutting, the rock at the bottom of the hole fractures at any time due to vibration excitation. The more the number of cracks, the smaller the elastic modulus will be. Therefore, the natural vibration frequency of rock affected by cracks formed on the rock can be analyzed by the following equation (Yang et al, 2007):

$$
\omega_{\mathrm{n}}=\sqrt{\frac{a S}{L_{\mathrm{y}} L m}}
$$

where $L$ is the length of the rock sample, $\mathrm{m} ; S$ is the crosssectional area of the rock sample, $\mathrm{m}^{2} ; L_{\mathrm{y}}$ is the length parameter of the crack, $\mathrm{m}$; $m$ is the rock sample mass, $\mathrm{kg}$; and $a$ is the surface energy per unit area, J.

Therefore, when the cracks in the rock are long, the rock resonant frequency is low, and then the amplitude of rock vibration may decrease, as shown in Fig. 15. The natural rock sample resonant frequency does change in the process of rock fragmentation. In order to make the rock resonate during rock fragmentation it is necessary to determine the appropriate frequency of the harmonic vibration, as shown in Fig. 15.

In practice, the harmonic generator is installed on the top of the drill bit as a nipple. The excitation vibration is transferred to the rock through the drill bit, which does not directly affect the upper drilling assembly. So the excitation frequency is not affected by the drilling assembly, but the impact-vibration response of rock is affected directly by the excitation mass and the device structure.

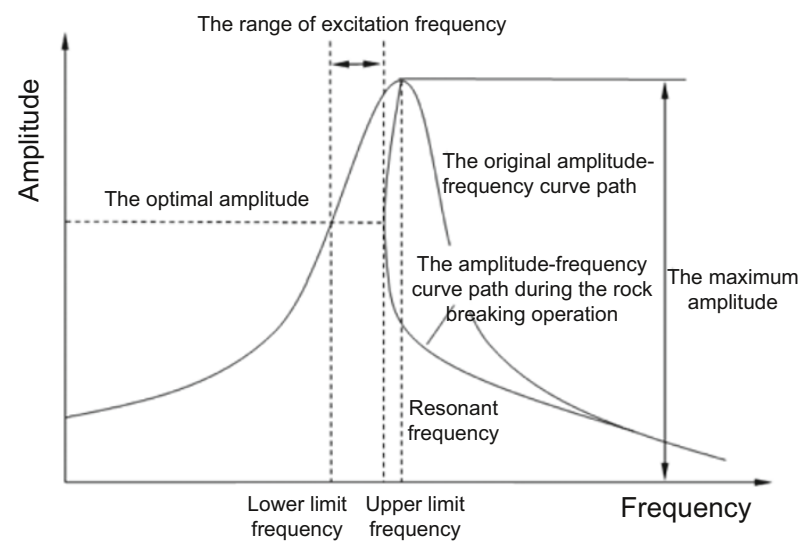

Fig. 15 Amplitude-frequency curve during resonance drilling

\section{Conclusions}

1) Experimental results show that the rock drillability decreased gradually with an increase in the harmonic vibration frequency during drilling with a micro PDC bit. At a vibration frequency of $1,500 \mathrm{~Hz}$, the rock drillability decreased by $25.6 \%$ and the rate of penetration (ROP) increased by $152 \%$.

2) The ROP of the micro PDC bit increased gradually with harmonic vibration frequency and achieved a maximum value at 1,400-1,500 Hz. The ROP increased by 93\%-106\%.

3) The ROP of the large size drill bit increased with rotary speed. It reaches a max value at a frequency of 1,400 $\mathrm{Hz}$ and its curve follows a power law. When the rotary speed approximated to $200 \mathrm{rpm}$, the rate of increase of ROP reduced.

4) The natural frequency of the rock sample was changing in the process of rock fragmentation. In order to make the rock resonate, it is necessary to determine the appropriate harmonic vibration frequency.

\section{Acknowledgements}

This study was funded by National Natural Science Foundation of China (Grant No. 51274072) and Youth Science Foundation of Heilongjiang Province (Grant No. QC2012C022).

\section{References}

Broer H W. Resonance and fractal geometry. Acta Applicandae Mathematicae. 2012. 120(1): 61-86

Cobern M E, Perry C A and Barbely J A. Drilling tests of an active vibration damper. SPE/IADC Drilling Conference, 20-22 February 2007, Amsterdam, the Netherlands (SPE 105400)

Cong J S, Wang X M, Xu D L, et al. Experimental measurement of acoustic resonance spectroscopy on artificial porous rock samples in a cylindrical resonance cavity. Science Bulletin. 2007. 52(21): 25642568 (in Chinese)

Egashira K, Mizutani T and Nagao T. Ultrasonic vibration drilling of microholes in glass. CIRP Annals-Manufacturing Technology. 2002. 51(1): 339-342

Eltrissi M M. Additional parameters for better vibration control. SPE/ IADC Middle East Drilling Technology Conference \& Exhibition, 26-28 October 2009, Manama, Bahrain (SPE/IADC 125457)

Flanders B A, Lynde G D, Tubel P S, et al. Resonance tools for use in wellbores. US Patent: 006009948. 4 January 2000

Gao Y and Gu L Z. Research situation of vibration drilling theory and optimizing parameter methods. Tool Engineering. 2008. 42(10): $27-$ 30 (in Chinese)

Gonzalez O, Bernat $\mathrm{H}$ and Moore $\mathrm{P}$. The extraction of mud-stuck tubulars using vibratory resonant techniques. SPE Annual Technical Conference and Exhibition, 11-14 November 2007, Anaheim, California, U.S.A. (SPE 109530)

Harris J M, Xu D L, Wang X M, et al. Resonance frequency shift in a cylindrical cavity with an inner small coaxial cylinder. Chinese Journal of Geophysics. 2005. 48(2): 493-500

$\mathrm{Hu} \mathrm{H} \mathrm{Y}$. The foundation of mechanical vibration. Beijing: Aerospace University Press. 2005 (in Chinese)

Ishikawa K, Suwabe H, Nishide T, et al. A study on combined vibration drilling by ultrasonic and low-frequency vibrations for hard and brittle materials. Precision Engineering. 1998. 22(4): 196-205

Jerry M H, Quan Y L and Xu C T. Differential acoustical resonance spectroscopy: An experimental method for estimating acoustic attenuation of porous media. 2005 SEG Annual Meeting, 2005. 6-11

Ksaibati K, Miley W and Armaghani J. Rubblization of concrete pavements. Transportation Research Record: Journal of the Transportation Research Board. 1999. 1684: 165-171

Li Y N. Some Nonlinear Problem Research in Vibration Utilizing 
Engineering. Ph.D. Thesis. Northeastern University. 1999. 22-44 (in Chinese)

Tichkiewitch S, Moraru G and Brun-Picard D, et al. Self-excited vibration drilling models and experiments. Manufacturing Technology. 2002. 51(1): 311-314

Wang X, Wang $\mathrm{L} J$ and Tao $\mathrm{J}$ P. Investigation on thrust in vibration drilling of fiber-reinforced plastics. Journal of Materials Processing Technology. 2004. 148(2): 239-244 (in Chinese)

Wiercigroch M. Resonance enhanced drilling: Method and apparatus. US Patent: 2010/0319994. 23 December 2010

$\mathrm{Wu} \mathrm{L}$, Zhang S Z and Lin F, et al. A review of modern rock breaking methods. Mineral Exploration Engineering. 2000. (2): 49-51 (in Chinese)
Yang W, Li L and Zhao Y X. Preliminary inquiry of theory of resonance rock breaking. Energy Technology and Management. 2007. 4: 7-9 (in Chinese)

Zhang D Y and Wang L J. Investigation of chipping in vibration drilling. Machine Tools and Manufacture. 1998. 38(3): 165-176 (in Chinese)

Zhang X N. Resonance crushing technology in the project of reconstruction of cement road surface. Traffic World. 2005. 2(3): 7274 (in Chinese)

Zou Z H, Zhou H W and Jiang F. Assessing the reliability of low frequencies in geophone records. 2010 SEG Denver Annual Meeting. 17-22 October 2010, Denver, Colorado

(Edited by Sun Yanhua) 